\title{
More-than-human infrastructural violence and more-than- human infrastructural justice: A case study of the Chad- Cameroon Pipeline Project
}

DOI:

10.1080/24694452.2020.1774348

\section{Document Version}

Accepted author manuscript

Link to publication record in Manchester Research Explorer

Citation for published version (APA):

Enns, C., \& Sneyd, A. (2020). More-than-human infrastructural violence and more-than-human infrastructural justice: A case study of the Chad-Cameroon Pipeline Project. Annals of the Association of American Geographers, 0, 0. [0]. https://doi.org/10.1080/24694452.2020.1774348

Published in:

Annals of the Association of American Geographers

\section{Citing this paper}

Please note that where the full-text provided on Manchester Research Explorer is the Author Accepted Manuscript or Proof version this may differ from the final Published version. If citing, it is advised that you check and use the publisher's definitive version.

\section{General rights}

Copyright and moral rights for the publications made accessible in the Research Explorer are retained by the authors and/or other copyright owners and it is a condition of accessing publications that users recognise and abide by the legal requirements associated with these rights.

\section{Takedown policy}

If you believe that this document breaches copyright please refer to the University of Manchester's Takedown Procedures [http://man.ac.uk/04Y6Bo] or contact uml.scholarlycommunications@manchester.ac.uk providing relevant details, so we can investigate your claim.

\section{OPEN ACCESS}




\section{Annals of the American Association Routledge of Geographers}

More-than-human infrastructural violence and more-thanhuman infrastructural justice: A case study of the ChadCameroon Pipeline Project

\begin{tabular}{|r|l|}
\hline Journal: & Annals of the American Association of Geographers \\
\hline Manuscript ID & AN-2019-1121.R2 \\
\hline Manuscript Type: & Regular Manuscript \\
\hline Manuscript Category: & Nature and Society \\
\hline Key Words: & $\begin{array}{l}\text { infrastructure, infrastructural violence, infrastructural justice, more-than- } \\
\text { human, Chad-Cameroon Pipeline Project }\end{array}$ \\
\hline \multicolumn{2}{|l}{} \\
\hline
\end{tabular}


More-than-human infrastructural violence and infrastructural justice: A case study of the Chad-Cameroon Pipeline Project

Charis Enns, Department of Geography, University of Sheffield Adam Sneyd, Department of Political Science, University of Guelph 


\begin{abstract}
As a new wave of infrastructure expansion takes place globally, there has been a parallel turn to infrastructure in geographical research. This article responds to recent calls within this research for less human-centred engagement with the infrastructure turn. More specifically, this article aims to destablise anthropocentric discussions about infrastructural violence and infrastructural justice. Using the Chad-Cameroon Pipeline Project as a case study, we advance two main points. First, we show that infrastructural violence is not always directed at humans. Rather, all agents, objects, and conditions - from humans to fish to carbon sequestration - entangled in webs of relations within zones of infrastructural expansion risk being subjected to violence when new and existing infrastructures meet. To illustrate this point, we detail two examples of competitions between new and existing infrastructures along the Chad-Cameroon Pipeline route, which together reveal the various forms of violence experienced by the more-than-human world when new infrastructural arrangements are layered on top of already existing ones. Second, we advance debates on infrastructural justice by adopting a more-than-human perspective in our conceptualization of this term. Recent writing on infrastructural justice has reflected on efforts to repair and rebuild infrastructures to produce more just futures (Sheller 2018). Drawing on the observations and reflections of our fieldwork along the Chad-Cameroon Pipeline route, we argue that just infrastructure projects must not only be inclusive of marginalized human and nonhuman populations, but they must also avoid interfering with the infrastructural work done by nature to sustain the more-than-human world.
\end{abstract}

\title{
Keywords
}

Chad-Cameroon Pipeline Project; infrastructure; infrastructural violence; infrastructural justice; more-than-human 


\section{Introduction}

The Chad-Cameroon Pipeline Project is a 1,070-kilometer pipeline that was built to transport oil from the Doba Region of southwestern Chad to a floating offshore storage (FSO) terminal just off the coast of southern Cameroon. From this FSO terminal, the oil is transported into tankers and exported to markets around the world. The pipeline project was initiated in the late 1990s, with construction on the subsea and offshore components of the project beginning in the early 2000s. To clear space for the construction of the subsea and offshore segment of the project, a reef was blasted using dynamite in a shallow bay near the coastal town of Kribi in southern Cameroon. A trench was then dug along the ocean floor to hold the pipeline. At the same time, the FSO was built by mooring an old crude oil tanker to the seabed about twelve kilomters off the coast.

A civil society advocate involved in documenting the impacts of the pipeline project explained during an interview how fishers were not permitted to set their nets within the general vicinity of construction activities, but access to the beach was restored and fishers were allowed to return to fishing in the shallow bay once pipeline construction was complete. However, upon their return, they noticed that certain species of fish had disappeared (civil society representative 1, Yaoundé, January 2017). Furthermore, several small oil spills from the FSO, as well as new restrictions on fishing close to the FSO, adversely impacted fishing livelihoods in and around Kribi over the coming years. The direct impacts of the pipeline on the coastal-marine ecosystem and, consequently, on fishing livelihoods have since been compounded by other changes taking place in the region, such as climate change and overfishing further out at sea (civil society representative 1, Yaoundé, January 2017). Combined, these changes have made increasingly difficult for the fishing communities to secure their livelihoods.

With the support of non-governmental organisations and legal advocates, fishing communities near Kribi submitted formal complaints to the consortium responsible for the pipeline project. The consortium responded with various initiatives to address the project's impact on the coastal-marine ecosystem and fishing-based livelihoods, but with little success. For example, in one village, Ébomé, which is directly along the pipeline route, the consortium agreed to finance an aquaculture project as reparations for the blasting of the reef. A local contractor was hired to construct two fishponds and source fingerlings for the ponds while the consortium had refrigerators delivered so that the fishers-turned-fish farmers would be able to 
transport their farmed fish to more distant markets. Recounting the failed aquaculture project, a village member from Ébomé explained:

Once the construction of the ponds was done, the fish started to grow. People from the village came to the ponds to see the fish. There was a lot of excitement. Then, poof! Rainy season came, and the fish washed out to sea. The fishponds were poorly designed...The contractors neglected to consider the flow of water. When it rained, the water could not drain from the ponds and so the water and the fish overflowed into the sea (Village member, Ébomé, February 2017).

Even if designed properly, the aquaculture project never had the potential to fully restore fishing livelihoods, as the fishponds did not mimic the ecological conditions of the shallow ocean bay prior to the destruction of the reef. As environmental activist and lawyer, Samuel Nguiffo, has argued, the fishponds were "far from being a fair replacement for the destruction of the reef: catches in fish ponds [could] be done only once or twice a year, compared to the previous daily fishing activities of the communities" (2005).

Infrastructural violence refers to "the interconnected ways that infrastructures participate in slow and structural, as well as more traditionally conceived, forms of violence" (Doherty 2019, S323). Rodgers and O'Neill's (2012) seminal work on infrastructural violence focuses on the structural forms of violence - including broader processes of marginalization, abjection, and disconnection - that flow through built infrastructure. They develop the concept in the special issue of a journal where each contribution reflects on how inclusion or exclusion from the design of infrastructure, access to infrastructure and provision of services through infrastructure can be linked to violent outcomes (Rodgers and O’Neill 2012). Beyond structural violence, the concept of infrastructural violence has also been used to describe the direct violence that can occur as a result of or through infrastructure. This includes: dispossession and displacement during the construction of new infrastructure (Roy 2011; Isaacman and Isaacman 2013); the risk and consequences of breakdown for those living in infrastructural spaces (Chu 2014); violent encounters between users of infrastructure (Danielak 2019); and the possibility of critical infrastructures becoming a target of violence with ripple effects for surrounding populations (Rao 2007; Graham 2010).

Problematically, however, the question of how the more-than-human world experiences infrastructural violence has been a relative blind spot within existing literature. This reflects a much broader trend within research on violence where violence tends to stand awkwardly in 
respect to the environment - "present and yet frequently hidden" by analyses - and, as a result, seriously undertheorized (Peluso and Watts 2001, 6). Referring back to the above story, it is clear that human-centered analyses of infrastructural violence risk resulting in tunnel vision, as the violence enacted on the human world overshadows the violence enacted on nonhuman species, broader ecosystems, and more-than-human relations. In this case, the infrastructural violence experienced by fishers as a result of the pipeline is intimately entwined with the violence experienced by the marine environment during the construction of offshore components of the project. Furthermore, while what typically comes to mind when we think of infrastructures are concrete socio-technical systems, such as pipelines, roads, railway lines, cables, and wires (Anand, Gupta, and Appel 2018; Cowen 2018), nature also functions as infrastructure and even seemingly technical infrastructures are comprised of both lively and non-lively entities (Carse 2012, 2014; Fredericks 2014). Thus, the layering of new infrastructural arrangements on top of existing ones - such as the layering of the pipeline on top of the reef - does more than expose both humans and nonhumans to various forms of risk and violence. It also threatens the mobilities and severs ecological, social, and economic relations made possible by existing infrastructural arrangements, such as healthy spawning grounds that sustain both fish populations and fishing communities' livelihoods.

Contributing to critical infrastructure studies, this article aims to destablise anthropocentric (human-centred) discussions about infrastructural violence and infrastructural justice. Using the Chad-Cameroon Pipeline Project as a case study, we advance two main points. First, we show that infrastructural violence is not always directed at humans. Rather, all agents, objects, and conditions - from humans to fish to carbon sequestration - entangled in webs of relations within zones of infrastructural expansion risk being subjected to violence when new and existing infrastructures meet. To illustrate this point, we detail two examples of competitions between new and existing infrastructures along the Chad-Cameroon Pipeline route, which together reveal the various forms of violence experienced by the more-than-human world when new infrastructural arrangements are layered on top of already existing ones. Second, we advance debates on infrastructural justice by adopting a more-than-human perspective in our conceptualization of this term. Recent writing on infrastructural justice has reflected on efforts to repair and rebuild infrastructures to produce more just futures (Sheller 2018). Drawing on the observations and reflections of our fieldwork along the Chad-Cameroon Pipeline route, we argue 
that just infrastructure projects must not only be inclusive of marginalized human and nonhuman populations, but they must also avoid interfering with the infrastructural work done by nature to sustain the more-than-human world.

Our analysis is informed by policy documents, images and videos, articles, and new media about the Chad-Cameroon Pipeline Project produced between 1997 and 2011, as well as fieldwork carried out in Cameroon between January and February 2017. This fieldwork consisted of ten key informant interviews with former employees of the pipeline consortium, local authorities, and representatives of civil society organizations, and four focus group discussions in four villages impacted by the construction of the Chad-Cameroon Pipeline with seventy-eight participants in total. Interviews and focus group discussions were carried out in English, French or Bagyéli, depending on the preference of the participants.

We also conducted multiple visits to sites along the pipeline route - driving by car or motorbike before continuing on foot to spaces where new and existing infrastructures came into contact along the Chad-Cameroon Pipeline Route. This part of our methodology can be described as a tour of infrastructural zones. As Dowling, Lloyd, and Suchet-Pearson write, the "tour" can be used to supplement interviews when conducting more-than-human research as "moving, attending, working, walking, talking, doing and picturing... encourage guides - human and nonhuman - to share their expertise" $(2016,825)$. Our visits to sites along the pipeline route were led by people living in villages along the pipeline route with in-depth understanding of how the pipeline impacted local mobilities, ecologies, socialities, and economies. These visits involved observational walks accompanied by discussions about the impacts of the pipeline. ${ }^{\mathrm{i}}$

\section{More-than-human infrastructures}

Before proceeding with our analysis of more-than-human infrastructural violence along the Chad-Cameroon Pipeline Route, we briefly situate our contribution within recent on infrastructure. Social science and humanities scholars often viewed infrastructure as a technical apparatus to be studied by engineers and planners in the past (McFarlane and Rutherford 2008). Although infrastructure "lurked in the background" of their research, they were not keen to embrace it as the central analytic and object of study (Anand, Gupta, and Appel 2018,4). However, as a new global infrastructure scramble has unfolded in recent years (Kanai and Schindler 2018), there has been a parallel turn to infrastructure in the social sciences and 
humanities and a growing body of interdisciplinary scholarship is now coalescing around the idea of critical infrastructure studies.

This scholarship defines infrastructure as built networks that facilitate flows of people and materials necessary for sustaining society. This definition is informed by the work of scholars such as Bowker (1994), Star (1999), Star and Ruhleder (1996) and Larkin (2013). These scholars use the term infrastructure to refer to the built systems - including pipelines, roads, railway lines, cables, and wires - that are essential for "securing bodies, materials, and processes [and] providing the logistical undergirding of the liberal capitalist order" (Wakefield 2019, 4; also see: Dillon and Reid 2009; Wakefield 2018). At the same time, this literature has shown that infrastructure does not service and sustain all societies and economies in the same ways. Rather, historic and contemporary social, political, and economic inequalities are often (re)produced and entrenched through infrastructure (Graham and Marvin 2001; Larkin 2013; Desai, McFarlane and Graham 2015; Anand 2017; Enns and Bersaglio 2020). In these ways, the critical infrastructure studies literature has convincingly made the argument that infrastructure is far more than a technical project that should be left in the realm of engineering and planning: It is also shaped by, and has profound consequences on, economic, political, and social life and, thus, warrants critical and interdisciplinary attention (McFarlane and Rutherford 2008; Enns 2019; Wakefield 2019; Lemanski 2019).

One critique of the critical infrastructure studies literature is that it has been overly anthropocentric in its focus. There has been a tendency to conceptualise infrastructure as built additions that are "added on top of, or sunk into, nature" yet distinct from nature (Jenson 2017 , 227). Infrastructure is often described as something built to assert control over nature - a means of demonstrating state power, securing certain forms of life, and transforming "inert nature into productive flows for commerce..." (Wakefield 2019, 4; also see: Akhter 2015, 2019; Mullenite 2019). From this perspective, the environment precedes infrastructure and can be transformed by infrastructure but it is not part of infrastructure (Jenson 2017; Hetherington 2019). This conceptualisation of infrastructure reflects an artificial divide between society, technology, and the environment that is problematic: Treating the nonhuman environment as the 'static backdrop' for infrastructure development (Pritchard 2011, as cited by Carse 2014, 227) may lead us to think and act as though society and technology exist in a world that is disconnected from nature rather 
than recognising that society, technology, and nature are all intimately entwined - as are our futures.

In response to this critique, some recent writing has attempted to make nature more visible in its analyses (Carse 2012, 2014; Howe et al. 2015; Jensen and Morita 2015; Wakefield 2018; Hetherington 2019; Wakefield and Braun 2019; Joniak-Lüthi 2020). This work does not limit its focus to technical systems or engineered networks. Rather, it brings to the fore the 'infrastructural work' (Bowker 1994, 10) that is done by all systems that facilitates flows of life and materials across space and time. This includes socio-natural landscapes that form the basis of built infrastructural arrangements, such as dammed rivers and canalled waterways (Carse 2012). Such work shows how built infrastructures are not simply 'added on top of nature' but inseparable from the natural, geological, atmospheric, and biological landscapes on which they are constructed (Carse 2012; Howe et al. 2016; Jenson 2017). Some scholars have also considered how nature functions as infrastructure in and of itself. The terms natural infrastructure or ecological infrastructure have been used to describe natural features that make and maintain connections that are essential for human and nonhuman life, such as wetlands that absorb and redirect water to alleviate floods, watersheds that deliver essential services to surrounding human and nonhuman populations, and oysters that protect coastal communities from storm surges (Lewis and Ernstson 2017; Wakefield 2019). Thus, rather than treating the nonhuman world as the static backdrop upon which infrastructure development unfolds, this research draws the more-than-human world into analyses of infrastructure right alongside society and technology.

Once the more-than-human world is recognised as infrastructural, researchers interested in infrastructure are not only obliged to pay attention to the infrastructural work done by nature to sustain diverse ecologies, societies, and economies: They must also become more attentive to the complex and often conflictual relations and interdependencies across the more-than-human world in infrastructural space. As Jenson and Morita argue, new modes of attention, description, and conceptualization are needed that are "capable of getting into view nonhuman agencies without letting go of human ones" $(2016,622)$. In the sections that follow, we show how stretching the concepts of infrastructural violence and infrastructural justice to encompass the more-than-human world enable us to do just this using the Chad-Cameroon Pipeline Project as a case study. 


\section{The Chad-Cameroon Pipeline Project and more-than-human infrastructural violence}

When construction began on the Chad-Cameroon Pipeline Project in 2000, it was the largest extractive infrastructure development ever built in Africa. At the time, it was estimated that the project would cost US $\$ 3.7$ billion to complete, requiring unprecedented foreign investment. Securing this investment was challenging as many saw risks with moving oil from Chad through Cameroon. To build investor confidence, the consortium of companies behind the project enlisted the help of the World Bank to defray risks. The World Bank characterized its role as the project's moral compass, working with the Chadian and Cameroonian governments to identify the benefits of the project and to develop environmental and social standards and management plans to mitigate risks. At the time, the World Bank was confident that the pipeline could be implemented in a way that would "lever for economic growth and sustainable development, attracting investment, creating jobs, and improving conditions in the countryside" (Oyono, Ribot and Larson 2006, 16).

Once the participation of the World Bank was secured, private financing soon followed and the project moved ahead quite quickly. Construction on the pipeline project was completed approximately one year ahead of schedule. In 2003, oil began to flow and exports commenced shortly thereafter. Although the World Bank's involvement in the project was important politically, the financial role that it played was comparatively small. Most of the financing for the project was raised by the consortium of companies that maintains controlling shares today, including ExxonMobil (40 percent), Petronas (35 percent), and Chevron (25 percent). The Government of Chad and Government of Cameroon are also each part of the consortium through their minority shares (approximately 3 percent combined) in the Tchad Oil Transportation Company (TOTCO) and the Cameroon Oil Transportation Company (COTCO) respectively.

Oil is extracted in Chad, but the majority of the pipeline project - around 800-kilometers of the 1,070-kilometer pipeline, two pump stations, a pressure reduction station, and the FSO - is in Cameroon (see Figure 1). As the pipeline traverses across the country towards the coast, it cuts through 241 villages and passes within two kilometers of hundreds of other villages (World Bank 2009). Along this route, the pipeline criss-crosses through fields, forests, and other waterways that farmers, fishers, and hunter-gatherers depend on for their livelihoods and cultural grounding, including important sacred sites (Nelson, Kenrick, and Jackson 2001). In total, the pipeline crosses seventeen major rivers that are used by communities for drinking, bathing, and washing 
(Keenan 2005).

The pipeline also runs near numerous protected areas, presenting further risks to Cameroon's environment and biodiversity. In central Cameroon, the pipeline passes alongside the Deng Deng Forest, which is home to rare plant life and endangered species. As the pipeline approaches the coast, it traverses Cameroon's Atlantic Littoral Forest, which hosts rare plant and animal species, including chimpanzees, elephants, gorillas, and pangolin. Once it reaches the coast, the pipeline runs near a national coastal reserve that was created to preserve endangered marine life and the Lobé Waterfalls, one of the world's few waterfalls that flows directly into the ocean (Horta 1997). In addition to having direct impacts on these areas during construction, the pipeline also poses an ongoing risk to these protected land and marine ecosystems. In recent years, civil society organisations have documented multiple minor spills along the pipeline route, including offshores leaks as oil has been offloaded from the terminal onto oil tankers (Civil society representative 1, Yaoundé, January 2017).

Despite the risks associated with the pipeline project for Cameroon, the revenues derived from the project by the government are relatively minimal. In exchange for serving as a transport conduit for Chad's landlocked oil, the Government of Cameroon earns a transit fee - which was fixed at the time of construction - as well as income tax and dividends through its shares in COTCO. At the outset of the project, it was estimated that there would be earnings of approximately US $\$ 500$ million for the Government of Cameroon over the course of its 25 to 30 year lifespan. In comparison, the Government of Chad was expected to earn US \$2 billion and private companies involved were expected to collectively earn nearly US \$7 billion (World Bank 2009). By the close of 2008, Chad's government revenue from oil was "almost $\$ 4.4$ billion seventeen times what had been projected and almost twice as much as non-oil revenue from all sources" - as a result of high oil prices (World Bank 2009, 13). In contrast, Cameroon's revenues were around \$200 million, which was lower than expected due to less production than originally anticipated (World Bank 2009).

\section{More-than-human infrastructural violence where the pipeline meets the sea}

Where the Chad-Cameroon Pipeline meets the sea near the coastal town of Kribi in southern Cameroon, coastal fishing communities have historically benefited from a vibrant local fishing economy. Their fishing livelihoods have been supported by a natural reef close to the shore and a 
second reef between 8 and 10 kilometres off of the coast - both of which served as an important habitat for several species of fish (Nguiffo 2005). Some fishers in the area used motorboats to lay nets at the more distant reef; however, many sustained their livelihoods using traditional paddle canoes and ocean nets at the reef closer to the shore (Nguiffo 2005). For communities in this area, the reefs in the shallow ocean bay hold more than economic value alone. The reefs were also seen as sacred sites: "the home of the "mami wata" or water spirits, who were responsible, among other things, for attracting the fish and putting them at the disposal of the village. The destruction of the reef was said to have angered and driven off the spirits" (Nguiffo 2014). Thus, in addition to serving as natural infrastructure - providing ecosystem services and making and maintaining the connections that are essential for coastal ecologies, societies, and economies the coastal-marine ecosystem also held significant cultural value for coastal fishing communities.

Following the construction of the pipeline, many fishers noticed changes in their fishing grounds. As a village leader living along the pipeline route explained during one interview: "We now must work far harder to earn far less. The pipeline had a large impact on fishing in the ocean. [The consortium] did certain things to make up for this but not enough ... They blasted the reef and then they abandoned us" (Village leader, Ébomé, Feburary 2017). Changes experienced by the fishing communities partly relate to the blasting of the nearby reef and multiple oil spills in the ocean bay over the past two decades. According to Alemagi, "Barracudas, snappers, and groupers are typical examples of fish species that are under threat as a result of habitat destruction of aquatic ecosystems from industrial activities including the oil industry along the Atlantic coast of Cameroon" $(2007,139)$. At the same time, other changes in the region, such as climate change and a growing commercial fishing industry further out at sea, have exasperated the impacts of the pipeline. Together, these changes have contributed to a larger ecological regime shift - namely, an abrupt change in the ecosystem, transforming relations amongst humans, animals, and vegetation (Lewis and Ernstson 2017). As a result of this ecological regime shift, the coastal-marine ecosystem can no longer carry out the same infrastructural work that it did in the past.

Affected communities spent years requesting that the adverse impacts of the pipeline on the coastal-marine ecosystem, and the coral reef in particular, be addressed. Representatives of COTCO held public forums with affected villages prior to pipeline construction; however, once construction was complete, affected communities found "it became impossible to talk to 
someone from COTCO” (community leader, Ébomé, Feburary 2017). In 2005, more than four years following the destruction of the reef, affected communities supported by non-governmental organisations and legal advocates finally had their concerns heard when they began dialogues with the consortium responsible for the pipeline project. When these dialogues failed to produce results, a formal mediation process began in 2011, overseen by the World Bank's Compliance Advisor/Ombudsman (CAO) - an independent recourse mechanism set-up to address complaints against the private sector lending arms of the World Bank Group. It was during this time that the consortium was finally persuaded to take certain steps to mitigate against the damages caused by the subsea and offshore components of the pipeline project, such as financing an aquaculture project for affected communities as discussed in the introduction of this article.

One of the most significant endeavours undertaken by the consortium as part of the formal mediation process was to replace the natural reef that it destroyed with an artificial reef. The artificial reef was constructed by linking together recycled tires, stainless steel straps, and the base of a barge. The barge base was then filled with water, allowing the reef to be sunk and secured to the ocean floor about 15 meters below the surface of the water and 1.5 kilometers north of the pipeline right-of-way. During an interview with a former consortium employee, a celebration ceremony was described, where the company invited affected communities to observe the sinking of the reef as evidence of the lengths being taken to deal with community complaints (Yaoundé, February 2017). A few years after the artificial reef was sunk, the consortium had a team of divers shoot underwater video footage that they claimed provided evidence that the reef had been colonized by aquaculture, including plants, phytoplankton, and fish - although this footage was never shared with fishing communities. Around the same time, the consortium also conducted an inspection of the entire offshore export system. It released a report following this inspection stating that both the submarine pipeline and FSO were found to be "teeming with fish and other marine life" and serving as "an artificial reef, acting as habitat for fish" (Esso 2008, 47).

Yet, coastal fishing communities contest these claims. They say that while some smaller species of fish can be found around the artificial reef, submarine pipeline, and FSO, other species previously common in the area have never repopulated the bay and that the size of all fish remains smaller than before (Village leader 1, Ébomé, Feburary 2017; Village leader 2, Ébomé, Feburary 2017). This claim is backed by environmental non-governmental organisations that 
continue to monitor and document the impacts of the pipeline. As one civil society organisation explained during an interview, any claim made by the consortium to have restored the ecosystem was unsubstantiated: As "there are no baseline statistics available for the relevant periods before and after the destruction of the natural reef and for the period before and after the laying of the artificial reef, the consortium cannot claim that the artificial reef restored the health of the aquatic ecosystem" (CSO representative, Yaoundé, January 2017). To make matters worse, fishers report that their nets regularly get caught and tear while they try to fish as parts of the artificial reef have come lose over time from the barge base.

Evidently, the Chad-Cameroon Pipeline resulted in the enactment of infrastructural violence against coastal fishing communities in Cameroon. This infrastructural violence took multiple forms. It included traditionally conceived forms of violence - namely, violence that is immediate, explosive, and spectacular. Community leaders in Ébomé recounted visible moments of violence during pipeline construction as heavy machinery and dynamite blasting was used to destroy coral and rocks to make way for the pipeline without the consent of local communities. At the same time, the pipeline also resulted in slow violence - "violence that is neither spectacular nor instantaneous but rather incremental and accretive, its calamitous repercussions playing out across a range of temporal scales" (Nixon 2011,2). For example, the impacts of the blasting of coral and rocks and the subsequent installation of the pipeline were not all felt immediately but played out across space and time. As Murry eloquently argues, people experienced "displacement in-place" as the pipeline slowly transformed the landscape, "leaving them displaced-at-home with contaminated water sources, soil erosion, deforestation, and oil spill pollution" (2015, 19; for more on displacement in-place, see: Magaramombe (2008), Nixon (2011) and Mollett (2014)). The infrastructural violence caused by the pipeline was also structural as the pipeline was constructed directly through villages that it was not intended to service and that already experienced various forms of infrastructural deprivation, including inadequate roads and inconsistent electricity (Village leader, Ébomé, Feburary 2017). Physical exclusion from the services that the Chad-Cameroon Pipeline Project only serves to furthers the social exclusion and inequality experienced by poor and marginalised rural groups of society along Cameroon's coast.

However, focusing on the human experience of infrastructural violence alone results in an anthropocentric analysis that overlooks the various ways in which the pipeline project also 
enacted violence against nonhuman species, larger ecosystems, and more-than-human relations. Prior to being blasted, the coral reef provided shelter from tidal waters, supporting spawning, and creating safe nursery grounds for juvenile species to develop and feed. In addition to sustaining nonhuman life, this shelter ensured that economically important fish species - such as barracudas, snappers, and groupers - could grow and later be caught, thereby sustaining morethan-human relations between fish and fishing communities. At the same time, the coral reef also did other important infrastructural work for the more-than-human world. This included providing protection against storm surges and coastal erosion, consuming algae, and filtering water. When the subsea and offshore components of the pipeline were built, direct, and physical violence was enacted against the nonhuman world. Furthermore, the ecological infrastructure that preserved the landscape, afforded essential ecosystem services and protected the cultural heritage of fishing communities was destroyed.

The fact that the consortium was eventually convinced to address some of the violence that the pipeline project caused is notable, as it departs from other case studies in the region. For example, Appel (2012) shows that both the state and oil companies in Equatorial Guinea have worked hard to abdicate responsibility for the infrastructural violence they cause, thereby exasperating this violence. In contrast, the consortium eventually took some liability for the violence caused by the Chad-Cameroon Pipeline Project; however, they did so in a highly anthropocentric way. They attempted to restore the livelihoods of coastal fishing communities by installing an artificial reef and initiating small income-generating projects - such as the aquaculture project - yet they made no effort to redress the loss of nonhuman life and destruction of more-than-human relations caused by the pipeline. Even if the artificial reef had been a success in terms of reviving fishing livelihoods, it never had the potential to rectify the entirety of harms experienced by the more-than-human world. Not only did the natural coral reef hold irreplaceable cultural and spiritual value as the home of mami wata - linking the human and nonhuman world - but it also provided essential ecosystem services for the more-than-human world, such as water filtration, that an artificial reef comprised of plastic and rubber could not provide. This example illustrates the importance of bringing into view the more-than-human world in our conceptualisation of infrastructural violence. Limiting our understanding of infrastructural violence to the violence enacted against humans overlooks the myriad ways that the nonhuman world and more-than-human relations are also adversely impacted by new 
infrastructure projects and results in anthropocentric and, consequently, incomplete and ineffective responses to infrastructural violence.

\section{More-than-human infrastructural violence where the pipeline meets the forest}

Cameroon's littoral forests surround the coastal fishing communities of southern Cameroon. These forest, along with the humans and nonhumans living within them, were also impacted by the Chad-Cameroon Pipeline Project. The impacts of the pipeline project were particularly pronounced for indigenous Bagyéli communities - both because of their connection to and dependency on the forest, as well as their long-standing social and political marginalisation by other forest users and the Cameroonian state. At the time of pipeline construction, most Bagyéli were largely reliant on the forest for their livelihoods although few possessed property rights recognised by the state (Civil society representative 3, Kribi, February 2017). Today, most Bagyéli living near the pipeline route continue to practice mixed subsistence livelihood activities, often involving forest products. The forest acts as natural infrastructure for the Bagyéli - providing ecosystem services and making and maintaining connections that are essential the survival of indigenous forest communities.

As a result of industrial development, the expansion of conservation activities and pressures from the Cameroonian state, forest communities in Cameroon have been shifting towards more sedentary lifestyles for a number of decades. Although members of Bagyéli communities continue to hunt and gather across their ancestral lands, many spend more time in small villages that run along the road connecting Loldorf, Bipindi and Kribi, where social services - such as schools and health care facilities - also tend to cluster. This road was first constructed during the German colonial era and has since been used by missionaries, logging companies, and other extractive industries. It is this same road, which cuts directly through the ancestral lands of the Bagyéli, that the consortium selected as a rough guide to follow while constructing the Chad-Cameroon pipeline (World Bank 1997, v.7).

The first step of constructing the pipeline through the forest involved first clearing a strip of land between 30 and 60 meters wide parallel to the main road. During an interview with a former consortium employee, it was explained how large trees and shrubs were felled while the remaining vegetation was burned before a shallow trench was dug where the pipe was laid (former consortium employee, January 2017, Yaoundé). The construction process through the 
Bagyéli's ancestral territories - which the consortium referred to as the Indigenous Peoples Plan Area - took around six months to complete. Prior to construction, the consortium sent a team of GIS specialists, anthropologists, physicians, and nutritionists to conduct a survey of and consult with Bagyéli communities in the vicinity of the proposed pipeline route (World Bank 1999, v.7). Based on their consultations, the consortium concluded that the Bagyéli would only experience "temporary disturbances" as a result of pipeline construction and operation (World Bank 1999, v.7). For example, they argued that although gathering and hunting might be impacted in the short-term, plants cleared along the pipeline easement would grow back and wildlife would return as soon as pipeline construction was complete.

Today, many Bagyéli contest the consortium's assessment about the impacts of the pipeline on their livelihoods as well as their ancestral territories. Although the consortium continues to claim that all land was restored and returned for use as normal within six months of construction, at least two villages directly within the pipeline easement said that they were permanently relocated during pipeline construction (FGD 2 and 4, Lolodorf-Bipindi-Kribi Corridor, February 2017). Other villages report that they lost important cultural or sacred sites when the pipeline was built, including a graveyard in one case (FGD 3, Lolodorf-Bipindi-Kribi Corridor, February 2017). Furthermore, each of the four villages that participated in focus groups explained that they lost important forest products that they were never compensated for, such as fruit trees (FGD 1, 2, 3, and 4, Lolodorf-Bipindi-Kribi Corridor, February 2017). The consortium had initially promised in public forums that communities would be compensated for any wild forest resources lost during pipeline construction; yet, a former consortium employee explained that most Bagyéli were later deemed ineligible for this compensation because they tend to hold customary land and resource use rights, rather than legal rights, over land and forest products (former consortium employee, January 2017, Yaoundé).

As a result of the discrepancy between the consortium's claims that the impacts of the pipeline would be minimal and the actual experienced impacts of forest communities, complaints were submitted to the consortium and these complaints became part of the formal mediation process overseen by the World Bank's CAO in 2011. The consortium attempted to respond to some of these complaints through the Foundation for Environment and Development in Cameroon (FEDEC) - a foundation established by the consortium with the specific mandate of supporting development in forest communities in the vicinity of the pipeline route in order to 
offset damages caused by the pipeline project (World Bank 1999). FEDEC initiated various projects in indigenous forest communities, such as distributing seeds and saplings, loaning agricultural equipment, and providing training on how to use fertilizer and pest control. FEDEC also funded the construction of new education facilities, financed vocational training and implemented a project involving handing out identification cards and birth certificates in Bagyéli communities along the pipeline route. An unspoken, underlying theme of these projects is that they aim to support transitions from the informal to formal economy, arguably promoting an approach to development rooted in modernisation theory rather than supporting the "fundamental needs and desires of the Bagyéli" (Civil society representative 1, January 2017, Yaoundé).

In addition to often misaligning with the Bagyéli's own development priorities, the consortium's approach to resolving concerns from affected Bagyéli communities about the pipeline through FEDEC suggests an incomplete or misguided understanding about forest ecosystems, as well as the relations between forest ecologies and forest communities. Recognising the forest as a place where the Bagyéli harvest leaves, nuts, fruits, barks, honey, and meat for use and trade, the consortium was willing to implement developments projects through FEDEC to offset the direct impacts and monetary losses caused by pipeline construction. However, intact forest landscapes also do other important infrastructural work for nonhumans (Bowker 1994, 10). These landscapes make and maintain connections that are essential for both human and nonhuman life, including providing a wide array of ecosystem services, such as shelter and food, soil production, and carbon sequestration. Although the damage caused to the intact forest during by pipeline construction may have seemed temporary or inconsequential when observed through the narrow lens guiding environmental impact assessments (EIAs), during focus group discussions with affected communities it was repeatedly argued that the vegetation felled disrupted nonhuman species with implications for the overall health of the larger forest ecosystem as well (FGD 1, 2, 3, and 4, Lolodorf-Bipindi-Kribi Corridor, February 2017).

Furthermore, the forest landscape also forms the base on which the Bagyéli operate their social systems and holds significant cultural value. As a Bagyéli civil society advocate, explained during an interview, the forest is managed through social networks, where user rights are conferred for particular areas of the forest through generational transference (Civil society representative 3, February 2017, Kribi). The felling of trees and shrubs to create space for the 
pipeline severed links between the Bagyéli, the spirits of their ancestors, and future generations while at the same time disrupting their approach to managing the forest (Civil society representative 3, February 2017, Kribi). As one village leader explained during a focus group discussion:

If your grandmother used to collect mangos from a specific tree, she would take her children to do this and it would get passed on through the linage and it allows for food to be passed from family to family, but also the spirit of her ancestors to be remembered. That specific tree has an important spiritual and cultural value. When it gets cut down, that linage is also cut (FGD 1, Lolodorf-Bipindi-Kribi corridor, February 2017).

Such sentiments were reiterated by others, who explained how the forest was central to the identity of forest peoples, connecting them to ancestors (Civil society representative 3, February 2017, Kribi). Thus, although the economic impacts of pipeline construction on the forest certainly mattered to affected Bagyéli communities, their concerns extend far beyond economic impacts alone. For affected communities, the forest also provides cultural ecosystems services and sustains connections between humans and other forms of life that were severed by the pipeline project.

Still today, representatives of the consortium and forest communities disagree about the implications of building the pipeline through the forest landscape of southern Cameroon. For the consortium, the impacts of pipeline on the forest ecosystem and communities were minimal and the ongoing operation of the pipeline today is unobtrusive. In contrast, affected Bagyéli communities describe the impacts of the pipeline as violent and traumatic. The infrastructural violence they have experienced as a result of the pipeline has taken various forms. During the construction of the pipeline, some Bagyéli communities experienced violence that was physical and direct. As previously mentioned, two communities report being relocated during pipeline construction, although the consortium continues to contest these claims. One community that participated in a focus group discussion explained how they woke up to the sound of a bulldozer coming through their village to knock down dwellings in order to clear the pipeline route (FGD 2, Lolodorf-Bipindi-Kribi Corridor, February 2017). For others, the violence associated with the pipeline has been structural rather than direct. For example, as FEDEC has provided agricultural supplies, loans, and training to forest dwellers who have title to land, trees have been cleared along the pipeline route and agricultural activities have been expanded on land that Bagyéli 
communities would have used for other purposes in the past.

However, again, focusing on the human experience of infrastructural violence alone results in an anthropocentric analysis that ignores the various ways in which new infrastructure also enacts violence against the more-than-human world. At the time of the EIA in the late 1990s, the consortium claimed that the impacts of the pipeline on forest biodiversity would be temporary and minimal (World Bank 1999, v.7). Yet today, it is widely acknowledged that linear infrastructures, such as pipelines and power lines, alter and fragment habitats in ways that adversely impact biodiversity. For example, studies have found that pipelines result in: changes to the structure and composition of plant communities; the mortality of plant communities; the introduction of invasive species; and the creation of new physical and visual barriers for mammals (Richardsons et al. 2017). Participants in focus groups made claims in support of this research; for example, they explained how certain species of animals moved further into the forest following pipeline construction. While displacement as a result of infrastructure development is recognised as a form of infrastructural violence enacted against people, this same form of infrastructural violence is also enacted against nonhumans communities.

Importantly, when infrastructural violence is enacted against nonhumans is not experienced by nonhumans alone but rather it resonates across the more-than-human world. For example, the clear-felling of land along the pipeline route impacted the ability of the forest landscape to do infrastructural work that sustains both human and nonhuman life, such as providing clean air, shade, and habitat. This clear-felling also disrupted the relations between the Bagyéli and the forest that support the management of forest resources, such as generational transference of trees that guide sustainable harvesting practice. The pipeline also had less tangible impacts on the more-than-human world, such as severing connections between the human and nonhuman world. As a civil society advocate explained during an interview, "For the Bagyéli, living alongside a huge pipe is traumatic as the forest is seen as having important spiritual significance. The forest contains sacred sites and relations that were altered when ... the forest was cleared along the entire pipeline route" (Civil society representative 4, February 2017, Yaoundé).

The impacts of this infrastructural violence on the more-than-human world also extend far beyond the immediate footprint of the pipeline project. The infrastructural work done by the forest that was disrupted by the pipeline also has global implications as intact forested landscapes (IFLs) provide globally important environmental services, such as global climate change 
mitigation and protecting against global biodiversity loss (for more on the global significance of IFLs, see Fa et al. 2019). This further demonstrates the importance of acknowledging the morethan-human elements of infrastructural violence. Failing to consider how infrastructural violence impacts the more-than-human world results in an incomplete understanding of the various ways that new infrastructure projects can cause injury, suffering, and even death to both human and nonhuman lives while also severing relations between the human and nonhuman world.

\section{Reimagining more-than-human infrastructural justice}

In this final section, we reflect on how adopting a more-than-human approach to conceptualising infrastructural violence may also help us to reimagine infrastructural justice. Our understanding of infrastructural justice is informed by Sheller (2018), who suggests that infrastructural justice involves material connections that support inclusive movement and distribution of resources and capital while eschewing exclusion, displacement and processes of uneven accumulation. Here, we argue that embedding a more-than-human approach into this understanding of infrastructural justice is essential to producing more just infrastructural futures.

Jenson and Morita (2016) write that adopting a less anthropocentric approach to the study of infrastructure is not about making the human actor disappear altogether but instead about recognising how society, technology, and nature are all intimately linked. Similarly, we argue that a more-than-human understanding of infrastructural violence is not about ignoring the violence enacted against humans through infrastructure or equating the violence experienced by humans to the violence experienced by nonhumans. Rather, bringing the more-than-human world into the study of infrastructural violence serves as a step towards overcoming the artificial division between nature, society, and technology in infrastructure scholarship, planning, and policy. In much of the writing on infrastructural violence, as well as more practical efforts to mitigate the impacts of new infrastructure projects, there is a tendency to think and act as though the violence exerted against society by and through infrastructure exists in a world that is separate from nature. What we aim to show through our analysis of the Chad-Cameroon Pipeline Project is that all lives, materials, and processes - from humans to fish to rocks to carbon sequestration - entangled in webs of relationships within zones of infrastructural expansion risk being subjected to infrastructural violence rather than human lives alone. Infrastructural violence extends to the more-than-human world - enacting material and structural violence on both 
humans and nonhumans while also interfering with the important and life-sustaining infrastructural work that nature does.

What we find particularly useful about our analysis is that it illustrates how more-thanhuman infrastructural violence is not always intentional. As Rodgers and O'Neill (2012) write, active infrastructural violence implies a clear intent - by an individual or a social group - which does not always exist. In some cases, infrastructural violence against the more-than-human world may be a product of ignorance, short-sightedness, and bias or partial knowledge practices. For example, when a former consortium employee was asked during an interview why project documents claim that no Bagyéli communities were relocated during pipeline construction, they responded by saying: "The land easement for the pipeline did not intervene with any permanent housing structures ... It could have been that short-term dwellings were impacted but such impacts would be insignificant" (Yaoundé, February 2017, emphasis added). This statement demonstrates a lack of understanding about the seasonality of both the forest and hunter-gather livelihoods, which require transhumance. When the same employee was asked why the EIA failed to mention the blasting of the coral reef, they responded by saying: "The consortium did not become aware of the reef until a much later date, long after construction" (Yaoundé, February 2017). Although the EIA includes detailed notes about ocean surface topography, there is no reference to the coral reef or the presence of small-scale fisheries in the area (World Bank 1999, v.7; World Bank 2000, 143). In effect, the consortium and its consultants were blind to the multispecies infrastructures that the pipeline disrupted.

As Cronon (1992) and Tsing (2005) argue, colonial imaginaries of sparsely inhabited and pristine nature can render indigenous engagements with landscapes invisible. It is these imaginaries that leave actors, such as the consortium, blind to the ecological infrastructures that sustain human and nonhuman populations. In this particular case, the absence of concrete sociotechnical systems, such as pipelines, roads, railway lines, cables, and wires, made the landscape appear 'infrastructure-less' to the consortium. The reason we make this point is not to let the consortium off the hook, so to speak, but to show why infrastructural violence can take place even when it seems as though appropriate measures and precautions have been taken to prevent adverse impacts of new infrastructure projects. In the case of the Chad-Cameroon Pipeline Project, a state of the art EIA, which included 19 volumes totalling thousands of pages and the establishment of 2 separate monitoring groups, did not prevent infrastructural violence against 
the more-than-human world. As a result of the coloniality of power and knowledge (Mignolo 2007; Quijano 2007; Ndlovu-Gatsheni 2013), existing ways of organising the landscape to make and maintain connections that are essential for human and nonhuman life were overlooked, devalued and, ultimately, destroyed as a result of the pipeline project.

This point closely relates to discussions within critical infrastructure studies about the politics of (in)visibility of infrastructures. As Star and Ruhleder (1996) have argued, infrastructures are situated and one's relationship with any infrastructure is dependent on one's position in society. Thus, infrastructures often go unnoticed and remain invisible in their day-today functioning (Bowker and Star 1994). It is not until moments of breakdown, malfunction or crisis that infrastructures become visible to all (Star 1999; Anand 2011; Ishii 2017; Morita 2017). This can be seen in the case of the Chad-Cameroon Pipeline Project where the infrastructural work done by nature - be it by the forest or the coral reef - remained invisible to the consortium until a crisis was reached. The blasting of the reef and the felling of the forest resulted in complaints against the consortium, the initiation of a formal mediation process facilitated by the World Bank and, eventually, the implementation of mitigation measures at the expense of the consortium. Only through this crisis did all of the parties concerned become aware of the infrastructural work performed by nature and the ways in which the pipeline violently disrupted this work and caused injury to both human and nonhuman lives.

The problem is that by the time this point of crisis was reached, more-than-human infrastructures had already been subjected to violent and irreversible damage with implications for both human and nonhumans. As Li (2018) argues, it is impossible to revert to the status quo ante due to the scale and scope of land transformation caused by large-scale infrastructure projects. During focus group discussions, Bagyéli communities affected by the pipeline project were asked what could be done to rectify the situation given the irreparable destruction that had taken place. One man stated:

[The consortium] destroyed something, so they have a debt to pay. ... but this debt can never be made even with what the Bagyéli lost when the pipeline was built, so [the consortium] must continue to pay... The multi-generational value of that tree is very important: it costs more than could ever be replaced. Because multiple generations would have used what has been lost, multiple generations should now benefit. If benefits end now, the debt is not repaid (FGD 2, Ocean District, Cameroon, February 2017). 
The same question was posed to the village member from Ébomé mentioned at the beginning of this article. He pointed to the empty fish ponds in a state of total disrepair and replied:

The pipeline had a large impact on fishing in the ocean. [The consortium] did certain things to make up for this but it could never be enough for what we lost. They did small things, but after time has passed, this is all we have been left with. Frankly, they built this and then they abandoned us (Village member, Ébomé, February 2017).

Across these discussions, a reoccurring sentiment was that multiple people in the community argued that as long as the pipeline continues to enable flows of oil to pass through their villages, rivers and land, the consortium should continue to pay reparations for the lasting harm done at the outset of the project and the risk they now continue to bear.

The infrastructural violence caused by the Chad-Cameroon Pipeline Project was both fast and slow. The blasting of the reef and the felling of the forest were instantaneous and spectacular acts of direct violence against the more-than-human world. Today, the impacts of this violence continue to cause "a constant state of injury" (Mbembe 2003) - including hunger and illness, the effects of dispossession and "displacement in-place," and ongoing constraints on mobility as a result of efforts to secure the pipeline infrastructure (Murray 2015). Those impacted argue that they deserve constant reparations in return for this constant and irreversible harm. As Li writes, new infrastructure projects are violent because of the forms of life they harm and destroy but also because of "the futures they preclude, and the set of material, social and political relations they enable and fix in place" $(2018,330)$. As the pipeline was layered on top of existing infrastructural arrangements, it foreclosed certain mobilities and permanently severed ecological, social, and economic relations made possible by existing infrastructural arrangements while locking in place (Li 2018) new futures premised on fossil fuel extraction.

This leads us to suggest that achieving more-than-human infrastructural justice involves more than designing infrastructure projects that are inclusive and that eschew exclusion, displacement and processes of uneven accumulation. Infrastructural justice requires addressing the social and environmental inequalities inscribed in new infrastructure networks while also taking seriously the infrastructural work done by nature. Just infrastructure projects would avoid interfering with the systems and services provisioned by nature to sustain the more-than-human 
world - particularly because there is often no commensurable built infrastructure to replace ecological infrastructure once it is destroyed.

A key challenge of this endeavor is making the infrastructural work done by nature visible before a point of crisis is reached. One way this might be achieved is by redesigning mechanisms used to assess and address the impacts of new infrastructure investments in pursuit of more-than-human infrastructural justice. For example, EIAs could be designed to question what existing ecological infrastructures sustain lives in the project area, whether these infrastructures will be lost as landscapes are remade and who and what will be marginalised and subjected to violence as a result. Ultimately, space needs to be created with political processes for endogenous forms of knowledge to inform discussions about what counts as infrastructure as a step towards preventing the eraser of more-than-human infrastructures in investment planning and perpetuating more-than-human infrastructural violence.

\section{Conclusion}

The issue of more-than-human infrastructural violence is particularly pressing given the scale and scope of infrastructure development today. In the early 21 st century, we find ourselves in the midst of a new wave of global infrastructure expansion, including a rush to build roads, construct dams, unveil new mega-city projects and exploit energy. Much of this infrastructure is being built as part development corridors, which are networks of linear infrastructure and ports that facilitate flows of people, capital, and commodities between sites of production and markets. The rush to invest in the infrastructure sector extends to the oil and gas sector despite instability in global oil and gas prices and ongoing debates about the future of fossil fuels. In 2018, the Oil and Gas Journal reported that planned pipeline construction to be completed nearly doubled between 2017 and 2018 with 14,657 miles of pipelines are planned or under construction globally (Smith 2018). New oil and gas exploration projects in Africa are driving a notable percentage of this development. For example, financing is being sought for the Trans Saharan Gas pipeline, which would run between Nigeria and Algeria with a planned total length of 4,400 kilometre; the African Renaissance Project pipeline is being designed to move gas between Mozambique and South Africa with a proposed length of 2,600 kilometre; and the East African Crude Oil Pipeline will transport crude oil over 1,400 kilometers, running from Uganda's oil fields to the coast of Tanzania. 
At the very same moment that this new infrastructure scramble (Kanai and Schindler 2018) is unfolding, the world is also experiencing a dual crisis of rapid climate change and biodiversity loss. In 2019, an UN-sponsored report by the Intergovernmental Science-Policy Platform on Biodiversity and Ecosystem Services (IPBES) estimated that the global rate of species extinction is currently tens to hundreds of times higher than it has averaged over the past 10 million years (IPBES 2019). Although the causes of the climate change and biodiversity crises are multiple, inter-linked, and complex, the UN report specifically commented on the role of recent infrastructure expansion in the accelerating decline of the natural world (IPBES 2019). As new infrastructure projects crisscross grasslands, mangroves, forests, rivers, lakes, and ocean bays the myriad of natural systems that sustain both human and nonhuman life - new and existing infrastructures meet with violent outcomes. Not only do these infrastructures contribute to climate change by increasing transport emissions, but they also bisect and fragment ecologically sensitive habitats that provide important ecosystem services.

At the outset of this article, we suggested that academic literature has paid insufficient attention to more-than-human infrastructural violence instead focusing on the violence enacted against the human world through and by infrastructure. However, social movements globally have been much more attuned to the violence enacted on nonhuman species, broader ecosystems and more-than-human relations when new infrastructure investments are made. Both the \#NoDAPL movement and the Trans Mountain pipeline protests in North America exemplify movements against more-than-human infrastructural violence. In addition to resisting the impingement of infrastructure investments on indigenous sovereignty, these movements have been concerned with the implications of infrastructure on water and nonhuman lives, such as orca and chinook salmon, against infrastructural violence. Such movements provide further credence for destablising anthropocentric discussions about infrastructural violence and infrastructural justice in critical infrastructure studies literature. Given the rate of global infrastructure expansion, the contribution of this expansion to the global climate and biodiversity crises and the movements emerging in response, the need to understand, theorise, and mitigate more-than-human infrastructural violence is pressing. 
i The research informing this article was carried out as part of a larger SSHRC-funded project on commodity politics in Cameroon that involved Dr. Steffi Hamann (University of Guelph) and Brendan Schwartz (International Institute for Environment and Development). Brendan Swartz played a central role in facilitating the research discussed in this article due to his experience working with non-governmental organisations and communities along the pipeline route, and familiarity with the dispute resolution process between impacted communities and the pipeline consortium between 2010 and 2016. 


\section{References}

Akhter, M. 2015. Infrastructure nation: State space, hegemony, and hydraulic regionalism in Pakistan. Antipode 47(4): 849-870.

Akhter, M. 2019. Adjudicating infrastructure: Treaties, territories, hydropolitics. Environment and Planning E: Nature and Space 2(4): 831-849.

Alemagi, D., 2007. The oil industry along the Atlantic coast of Cameroon: assessing impacts and possible solutions. Resources Policy 32(3): 135-145.

Anand, N. 2017. Hydraulic city: Water and the infrastructures of citizenship in Mumbai. Durham, N.C.: Duke University Press.

Anand, N., Gupta, A., and Appel, H. (Eds.). 2018. The promise of infrastructure. Durham, N.C.: Duke University Press.

Appel, H. C. 2012. Walls and white elephants: Oil extraction, responsibility, and infrastructural violence in Equatorial Guinea. Ethnography, 13(4): 439-465.

Bowker, G. C. 1994. Science on the run: Information management and industrial geophysics at schlumberger, 1920-1940. Cambridge, MA: MIT Press.

Carse, A. 2012. Nature as infrastructure: Making and managing the Panama Canal watershed. Social Studies of Science 42(4): 539-563.

Carse, A. 2014. Beyond the Big Ditch: Politics, ecology, and infrastructure at the Panama Canal. Cambridge, Massachusetts: MIT Press.

Chu, J. Y. 2014. When infrastructures attack: The workings of disrepair in China. American Ethnologist 41(2): 351-367.

Cowen, D. 2018. Introduction. Investigating Infrastructures: Part II. Society and Space.

Cronon, W. 1992. A place for stories: Nature, history, and narrative. Journal of American History 78(4): 1347-1376.

Desai, R., McFarlane, C., and Graham, S. 2015. The politics of open defecation: informality, body, and infrastructure in Mumbai. Antipode 47(1): 98-120.

Danielak, S. 2019. Navigating urban encounters: an infrastructural perspective on violence in Johannesburg's taxi industry, Third World Thematics: A TWQ Journal: 4:2-3, 137157.

Dillon, M., and Reid, J. (2009). The liberal way of war: Killing to make life live. London and New York: Routledge. 
Doherty, J. 2019. Filthy flourishing: para-sites, animal infrastructure, and the waste frontier in Kampala. Current Anthropology, 60(S20): S000-S000.

Dowling, R., Lloyd, K., and Suchet-Pearson, S. 2017. Qualitative methods II: 'More-thanhuman' methodologies and/in praxis. Progress in Human Geography 41(6): 823-831.

Enns, C. 2019. Infrastructure projects and rural politics in northern Kenya: The use of divergent expertise to negotiate the terms of land deals for transport infrastructure. The Journal of Peasant Studies 46(2): 358-376.

Enns, C., and Bersaglio, B. 2019. On the Coloniality of "New" Mega-Infrastructure Projects in East Africa. Antipode.

Fa, J., Watson, J. E. M., Leiper, I., Potapov, P., Evans, T. D., Burgess, N. D. Z. Molnar and Austin, B. J. (2019). Importance of Indigenous Peoples' lands for the conservation of Intact Forest Landscapes. Frontiers in Ecology and the Environment.

Fredericks, R. 2014. Vital infrastructures of trash in Dakar. Comparative Studies of South Asia, Africa and the Middle East 34(3): 532-548.

Graham, S. (Ed.). 2010. Disrupted cities: When Infrastructure Fails. New York and London: Routledge.

Hetherington, K. 2019. Infrastructure, Environment, and Life in the Anthropocene. Durham, N.C.: Duke University Press.

Horta, K. 1997. Questions Concerning the World Bank and Chad/Cameroon Oil and Pipeline Project. Environmental Defense Fund, New York, New York, USA.

Howe, C., J. Lockrem, H. Appel, E. Hackett, D. Boyer, R. Hall and A. Ballestero. 2016. Paradoxical infrastructures: Ruins, retrofit, and risk. Science, Technology, \& Human Values 41(3): 547-565.

Isaacman, A. F., and Isaacman, B. S. 2013. Dams, displacement, and the delusion of development: Cahora Bassa and its legacies in Mozambique, 1965-2007. Athens, Ohio: Ohio University Press.

Ishii, M. 2017. Caring for divine infrastructures: nature and spirits in a special economic zone in India. Ethnos 82(4): 690-710.

Jensen, C. B. 2017. Pipe dreams: Sewage infrastructure and activity trails in Phnom Penh. Ethnos 82(4): 627-647.

Jensen, C. B., and A. Morita. 2017. Introduction: Infrastructures as Ontological Experiments. Ethnos 82(4): 615-626. 
Joniak-Lüthi, A. 2020. A road, a disappearing river and fragile connectivity in Sino-Inner Asian borderlands. Political Geography 78: 102122.

Kanai, J. M. and S. Schindler. 2018. Peri-urban promises of connectivity: Linking project-led polycentrism to the infrastructure scramble. Environment and Planning A: Economy and Space 0(00): 1-21.

Larkin, B. 2013. The politics and poetics of infrastructure. Annual review of anthropology 42: 327-343.

Lemanski, C. 2019. Infrastructural citizenship: the everyday citizenships of adapting and/or destroying public infrastructure in Cape Town, South Africa. Transactions of the Institute of British Geographers.

Lewis, J. A. and H. Ernstson. 2017. Contesting the coast: Ecosystems as infrastructure in the Mississippi River Delta. Progress in Planning 129: 1-30.

Li, T. M. 2018. After the land grab: Infrastructural violence and the "Mafia System" in Indonesia's oil palm plantation zones. Geoforum 96: 328-337.

Marvin, S. and Graham, S. 2001. Splintering Urbanism: networked infrastructures, technological mobilities and the urban condition. Taylor \& Francis.

Mbembe, A. 2003. Necropolitics. Public Culture 15(1): 11-40.

McFarlane, C., and J. Rutherford. 2008. Political infrastructures: Governing and experiencing the fabric of the city. International Journal of Urban and Regional Research 32(2): 363-374.

Mullenite, J. 2019. Infrastructure and Authoritarianism in the Land of Waters: A Genealogy of Flood Control in Guyana. Annals of the American Association of Geographers 109(2): 502-510.

Magaramombe, G. 2010. 'Displaced in Place': Agrarian Displacements, Replacements and Resettlement among Farm Workers in Mazowe District. Journal of Southern African Studies 36(2): 361-375.

Mignolo, W. D. (2007). Introduction: Coloniality of power and de-colonial thinking. Cultural studies 21(2-3), 155-167.

Morita, A. 2016. Infrastructuring amphibious space: the interplay of aquatic and terrestrial infrastructures in the Chao Phraya Delta in Thailand. Science as Culture 25(1): 117-140.

Morita, A. 2017. Multispecies Infrastructure: Infrastructural Inversion and Involutionary Entanglements in the Chao Phraya Delta, Thailand. Ethnos 82(4): 738-757.

Ndlovu-Gatsheni, S. J. (2013). Coloniality of power in postcolonial Africa. African Books 


\section{Collective.}

Nelson, J., Kenrick, J. and Jackson, D. 2001. Report on a Consultation with Bagyeli Pygmy communities impacted by the Chad-Cameroon oil-pipeline project. Centre pour l'Environnement et le développement. Association tchadienne pour la promotion et la défense des droits de l'Homme, Environmental Defense Fund, May 2001.

Nixon, R. 2011. Slow Violence and the Environmentalism of the Poor. Cambridge, Mass.: Harvard University Press.

Nguiffo, S. 2005. The goat grazes where it is tied: remarks on the neo-patrimonial administration of Cameroon's forestry sector. The need to control transnational forestry corporations: a European case study. Cambridge, UK.

Nguiffo, S. 2014. Infrastructure, development and natural resources in Africa: A few examples from Cameroon. Bulletin 203. Jul 4, 2014. Montevideo, Uruguay: World Rainforest Movement.

Oyono, P. R., Ribot, J. C., and Larson, A. M. 2006. Green and black gold in rural Cameroon: natural resources for local governance, justice and sustainability (No. Environmental Governance in Africa Working Paper Series (WRI) no. 22, p. 92p). World Resources Institute, Washington, DC, USA.

Peluso, N. L. and Watts, M. (Eds.). 2001. Violent environments. Ithaca, New York: Cornell University Press.

Quijano, A. (2007). Coloniality and modernity/rationality. Cultural studies 21(2-3), 168-178.

Rao, V. 2007. How to read a bomb: Scenes from Bombay's black Friday. Public Culture 19(3), 567-592.

Richardson, M. L., Wilson, B. A., Aiuto, D. A., Crosby, J. E., Alonso, A., Dallmeier, F., and Golinski, G. K. (2017). A review of the impact of pipelines and power lines on biodiversity and strategies for mitigation. Biodiversity and Conservation 26(8), 18011815.

Rodgers, D. and B. O’Neill. 2012. Infrastructural violence: Introduction to the special issue. Ethnography 13(4): 401-412.

Roy, A. 2011. The blockade of the world-class city: dialectical images of Indian urbanism. In Worlding cities: Asian experiments and the art of being global, ed. A. Roy and A. Ong, 259-278. New Jersey, New York: John Wiley \& Sons.

Sheller, M. 2018. Mobility justice: The politics of movement in an age of extremes. New York, New York: Verso Books. 
Smith, C. Near-term pipeline plans nearly double, future slows. Oil \& Gas Journal. Feb 5th, 2018

Star, S. L. 1999. The ethnography of infrastructure. American behavioral scientist 43(3): 377391.

Star, S. L. and Ruhleder, K. 1996. Steps toward an ecology of infrastructure: Design and access for large information spaces. Information systems research 7(1): 111-134.

Tsing, A. L. 2005. An ethnography of global connection. Friction. New Jersey, New York: Princeton University Press.

Wakefield, S. 2019. Making nature into infrastructure: The construction of oysters as a risk management solution in New York City. Environment and Planning E: Nature and Space.

Wakefield, S., and Braun, B. 2018. Oystertecture: Infrastructure, profanation and the sacred figure of the human. Infrastructure, Environment, and Life in the Anthropocene.

World Bank. 1997. Environmental Assessment: Chad Export Project (Cameroon Portion). October 1997. Washington, D.C.

World Bank. 2009. The World Bank Group Program of Support for the Chad Cameroon Petroleum Development and Pipeline Construction Program. Performance Assessment Report. Report No.: 50315. September 16, 2009 Washington, D.C. 


\section{Figure Caption:}

Figure 1: Map of the Chad-Cameroon Pipeline Project

\section{Author Biographies}

CHARIS ENNS is a Presidential Fellow in Socio-Environmental Systems at the Global Development Institute, University of Manchester, Manchester M13 9PL UK. She was previously a Lecturer in the Department of Geography at the University of Sheffield, UK. E-mail: charis.enns@manchester.ac.uk. Her research interests include the impacts of large-scale investments in land and natural resources on rural landscapes and livelihoods, with a focus on mega-infrastructure investments.

ADAM SNEYD is an Associate Professor in the Department of Political Science at the University of Guelph, Guelph ON N1G 2W1 Canada. Email: asneyd@uoguelph.ca. He is the author of Politics Rules: Power, Globalization and Development (Fernwood \& Practical Action 2019); Cotton (Polity 2016) and Governing Cotton: Globalization and Poverty in Africa (Palgrave: 2011). 


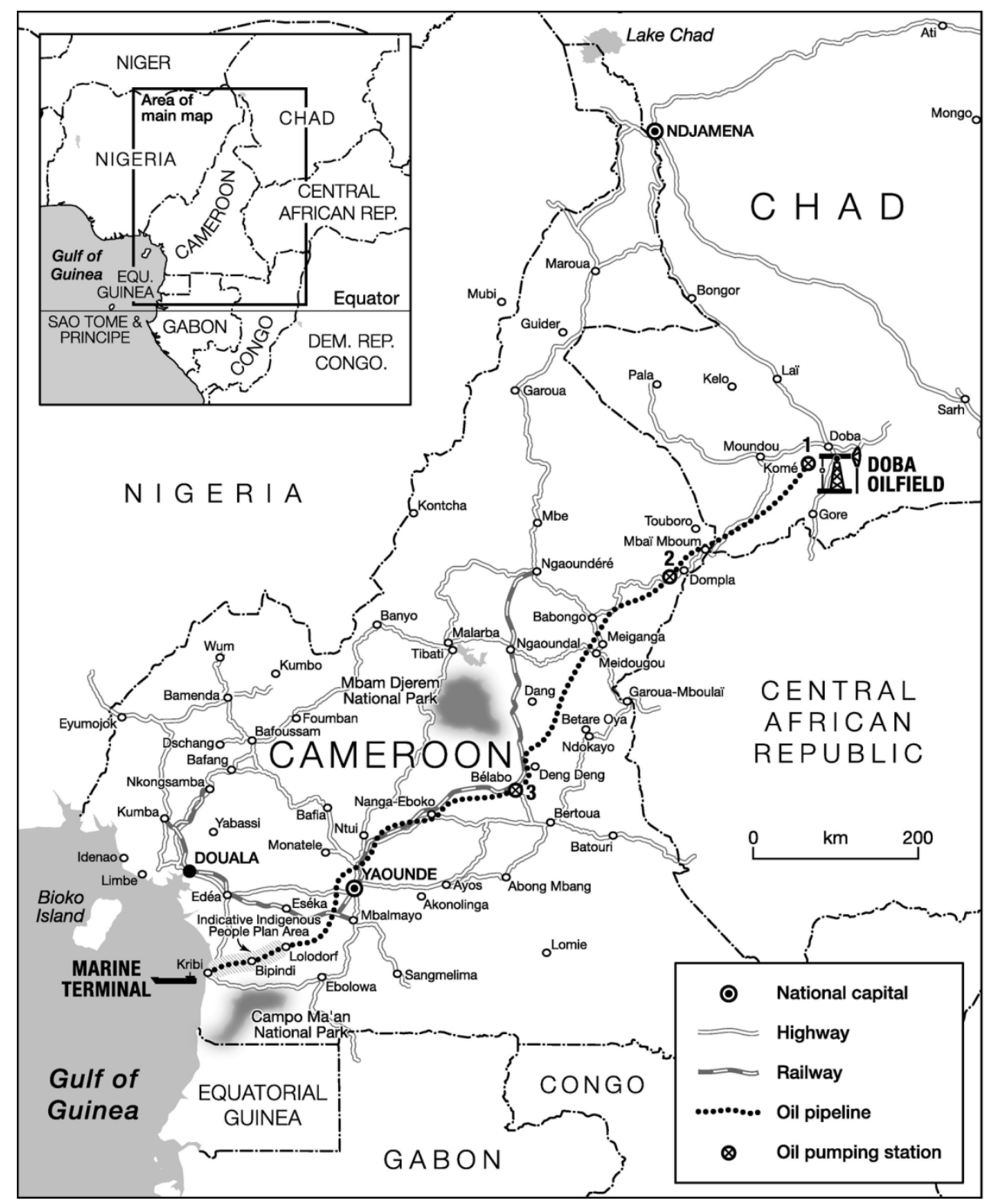

Figure 1: Map of the Chad-Cameroon Pipeline Project $134 \times 160 \mathrm{~mm}(300 \times 300$ DPI $)$ 